DOI 10.17816/transsyst201844146-156

(C) G. Q. Wang ${ }^{1}$, S. T. Hu ${ }^{1}$, G. F. Zeng ${ }^{1}$, F. Ye ${ }^{1}$, W. L. Xu ${ }^{2}$

${ }^{1}$ Tongji University

(Shanghai, China)

${ }^{2}$ CCCC Tunnel Engineering Company Limited

(Beijing, China)

\title{
GRAY RELATIONAL ANALYSIS BETWEEN THE MAGLEV- STRUCTURAL DEFORMATION AND CONSTRUCTION PARAMETERS OF THE SHIELD TUNNEL CROSSING THE SHANGHAI MAGLEV PROTECTED AREA
}

Background: Shanghai Maglev Demonstration Line is the only commercial high-speed maglev train line in the world, which has multiple functions such as transportation, exhibition, tourism and sightseeing. Besides, Shanghai Maglev Demonstration Line has been in operation for 15 years, and has been operating safely and punctually. Maglev protected area are located within 30 meters of the left and right sides of the Shanghai Maglev Demonstration Line and unrelated persons are not allowed to enter the area. When there were external construction invading the protected area, it is neccessary to do the comprehensive technical monitoring and protection. Without similar project to refer to, Metro Line 13 traversing Shanghai Maglev Line was a big challenge. Therefore, effective measures should be taken to do the comprehensive technical monitoring. Finding the relation between the maglev deformation and shield construction parameters was an important part of the monitoring.

Aim: This thesis aimed at finding the relation between the maglev deformation and shield construction parameters and controlling the maglev deformation in the crossing of Metro Line 13, thus guiding the shield construction.

Methods: This thesis calculated the gray relation between the maglev deformation and shield construction parameters from the cause of deformation of the maglev by the gray relation analysis.

Results: The construction parameters optimization and the sensitivity control are carried out. Meanwhile, combined with the measured results of deformation monitoring, the multi means parallel monitoring data are analyzed synthetically and the data are checked, and the construction parameters are adjusted reasonably to make the pier column deformation in the controllable permissible range, having ensured the safe operation of the maglev.

Conclusion: The calculation results has provided a reference for realizing active control on the influence of shield construction on the maglev and has remedied the defect that could only use deformation monitoring but could not control the deformation actively in the past work. The gray relational analysis has a certain effect on controlling the influence of shield construction on surrounding structures and has certain reference significance for subsequent similar projects.

Keywords: High-speed Maglev, Protection Zone, Comprehensive Technical Monitoring and Protection, Deformation Monitoring, Settlement, Gray Relation, Shield Construction Parameters 


\section{PROJECT PROFILE AND THE PROPOSAL OF THE PROBLEMS}

There were three lines traversing the maglev between pier 182 to pier 185 respectively of metro line 13, up line, down line and approaching line, the plan shown in Fig. 1. The maximum diameter was $6760 \mathrm{~mm}$ and the maximum burial depth was $18.65 \mathrm{~m}$ of the shield of which the third tunnel was a curve of $250 \mathrm{~m}$ radius, shown in Fig. 2. The construction face of the project was rather close to the maglev pile, leading to troublesome and risky construction. Deep soil in the vicinity of the shield would produce varying degrees of deformation in the course of shield tunneling, thus leading to the deformation of the maglev pile, cushion cap and column. The project metro line 13 traversing the maglev was a new challenge in the history of engineering technology. Meanwhile, the deformation were effectively controlled and the safe operation of the maglev was guaranteed through comprehensive technical monitoring and protection.

The construction sequence of the three tunnels was the upline, the downline and the approaching line. The upline and the downline being basically orthogonal to the maglev line, the construction of the two lines were relatively simple. For the construction of the third small radius curve, the relationship between the maglev deformation and the shield construction parameters within the scope of the project could be found in the course of the construction of the first two tunnels to guide

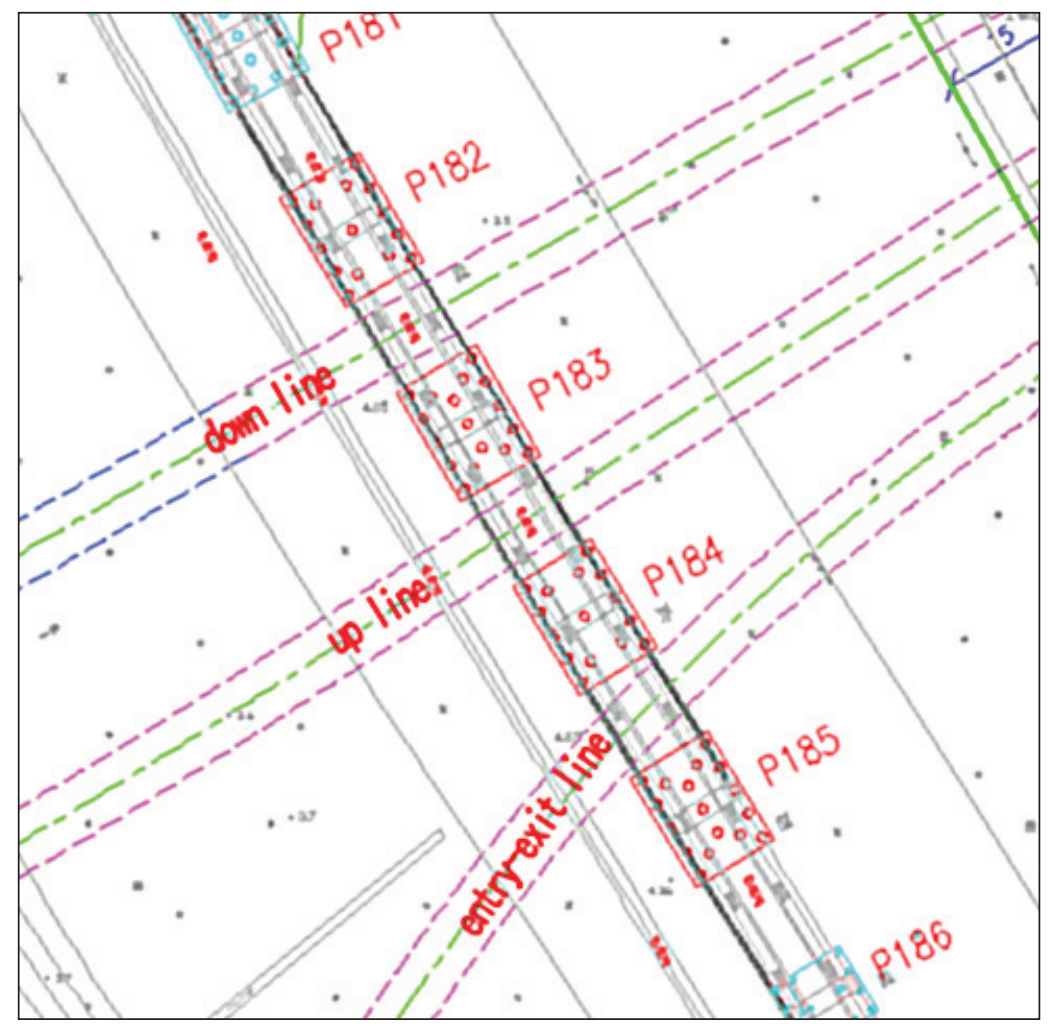

Fig. 1. Metro line13 traversing the maglev plane 


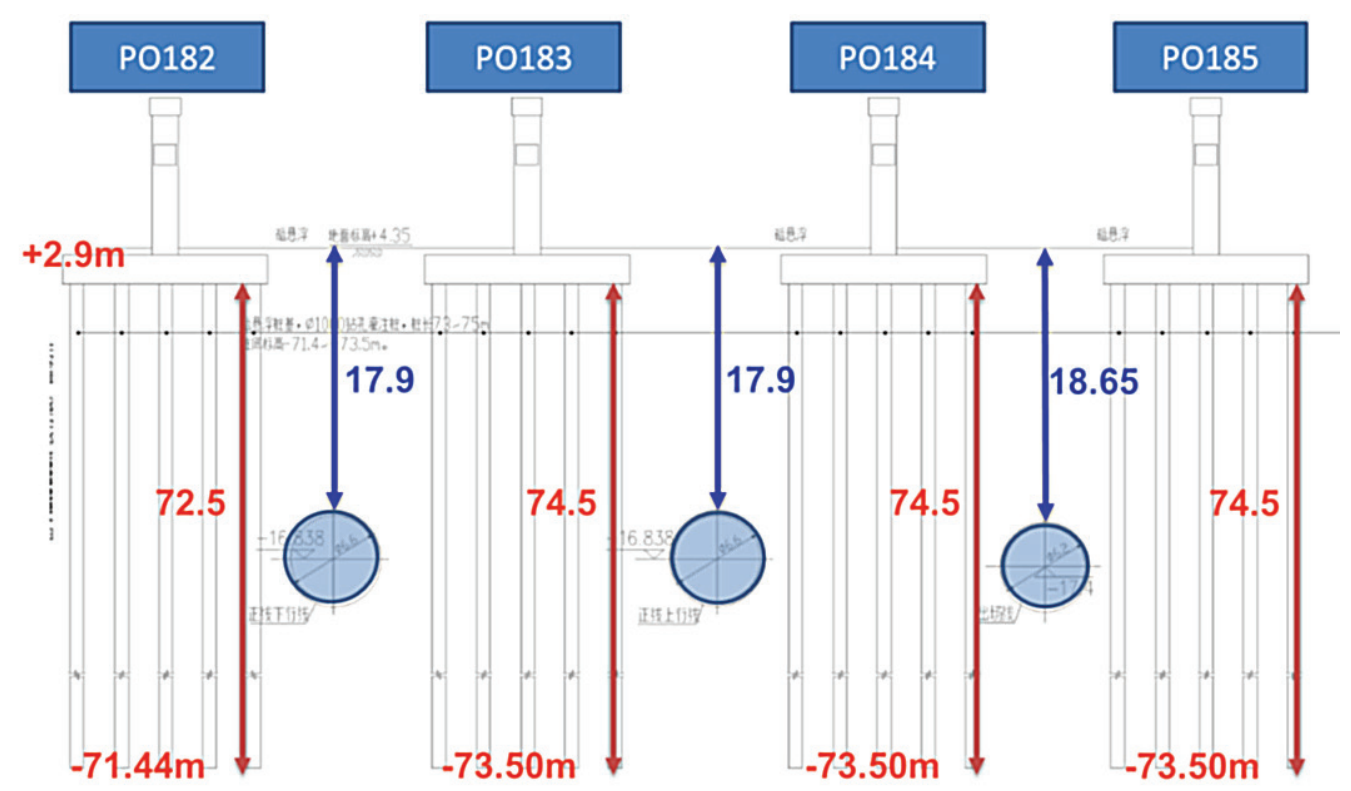

Fig. 2. The relationship between the maglev structure and the shield tunnel

the construction of the third tunnel. It was found in the project that the key to solve the problems was to study the gray correlation degree between varying construction parameters and the deformation of different reference points. On the bases of studying the deformation regularity between the construction parameters and the maglev structures of the first two tunnels, this thesis has calculated the gray correlation degree between the maglev deformation and the shield tunnel parameters during the third tunnel construction by setting simulative segment and then obtains the sensitivity sequence of the construction parameters to guide the optimization and adjustment of the construction parameters. The deformation of the surface and the maglev pile are well controlled.

\section{DEFORMATION REQUIREMENTS OF THE MAGLEV STRUCTURES AND MONITORING POINTS LAYOUT}

1. Deformation control value

According to the "Administrative Measures for Maglev Safety Protection Zone of Shanghai Maglev Transportation Development", combined with the relevant technical requirements of the maglev system, controlling value requirements of additional deformation produced from external engineering were shown as follows:

1). Total foundation settlement did not exceed $2 \mathrm{~mm}$ (accounting for $10 \%$ of the total design settlement); 
2). The cumulative uneven settlement of the front and rear support pier was not more than $1 \mathrm{~mm}$;

3 ). The cumulative lateral (y-direction) offset of the front and rear support pier was not more than $1 \mathrm{~mm}$;

4). The cumulative uneven settlement of the left and right support pier of the same cap was not more than $0.5 \mathrm{~mm}$.

2. Monitoring range and monitoring requirements.

1). Monitoring range.

The deformation monitoring was carried out for the piles and cable trenches in the range of the P0181 to P0186 maglev piles which were badly affected by the construction.

2). Monitoring points layout and monitoring requirements:

- Monitor the vertical deformation of the A and $\mathrm{B}$ rail piers in the above range and the tilting deformation of the $\mathrm{A}, \mathrm{B}$ rails crosswise bridge and along to the bridge, and calculate the $y$-direction offset corresponding to the function element for the tilt;

- Monitor the vertical deformation of the strong and weak cable trenches in the above ranges.

- Monitor Ground subsidence;

- Monitor Deep soil deformation.

The monitoring points layout shown above can accurately reflect the characteristics of the maglev deformation. The deformation value are reference sequence in the calculation of gray correlation degree in this paper of which monitoring accuracy badly affects the effectiveness of the calculation results. Therefore, it is needed to use high precision measurements to monitor the deformation.

\section{GRAY CORRELATION DEGREE ANALYSIS}

Gray system theory produces a concept that analyzes various elements by using gray correlation degree analysis, intending to find out the numerical relationship among all factors in a system. Thus, gray correlation degree analysis has provided a quantitative measure for the development of a system and is very suitable for dynamic process analysis. Gray system theory has been widely used in economy, science and technology, agriculture, industry, ecology and so on since the founding by professor Deng in 1982. Besides, the theory has been well applied in the field of engineering in the past ten years.

\section{Deng's correlation degree.}

For the elements between two systems, the dimension of relevance that changes with time or different objects is called gray correlation degree. In the 
system, if the trend of two elements is consistent, that is, the degree of synchronous change is relatively high, it is said that the degree of correlation between the two factors is relatively high, otherwise, it is relatively low. After the dimensionless treatment, the correlation coefficient of the comparison sequence for the reference sequence is calculated as follows:

$$
\zeta_{i}(k)=\frac{\min _{i} \min _{k}\left|x_{0}(k)-x_{i}(k)\right|+\rho \cdot \max _{i} \max _{k}\left|x_{0}(k)-x_{i}(k)\right|}{\left|x_{0}(k)-x_{i}(k)\right|+\rho \cdot \max _{i} \max _{k}\left|x_{0}(k)-x_{i}(k)\right|},
$$

where $K=1,2, \ldots, m ; j=1,2, \ldots n ; x_{0}^{(k)}$ is reference sequence, $x_{j}^{(k)}$ is comparison sequence, time dimension is $\mathrm{n}$.

Gray correlation degree of comparison factor for reference factor is calculated as follows:

$$
r_{o i}=\frac{1}{n} \sum_{k=1}^{n} \zeta(k)
$$

\section{General method for calculating gray correlation degree:}

The general steps for calculating gray correlation degree are shown as follows:

1). Determining reference sequences and comparison sequences

The sequences that reflect the behavior characteristics of the system are reference sequence. The sequences that affect the factor composition of behavior of the system are comparative sequences.

2). Dimensionless processing of data

Owing to the fact that the physical meaning of each factor in the system are different, the dimensions of the data are not necessarily the same. Therefore, it is not convenient to compare the factors, that is, it is difficult to obtain correct conclusions. So the dimensionless processing is usually carried out when doing the gray correlation analysis.

\section{3). Calculating correlation coefficient}

The correlation coefficient between comparison sequence and reference sequence is calculated and the correlation coefficient matrix is formed according to the formula (1).

4). Calculating gray correlation degree

For each factor in comparison sequences, the average value of correlation coefficients on time dimension is the gray correlation degree between the factor and the reference factor. In turn, the gray correlation degree matrix can be obtained.

5). Sorting of gray correlation degree

For one reference sequence, different evaluation indexes are sorted according to the gray correlation degree, thus the affecting factors being obtained. 
There are many methods to do dimensionless processing, such as the initial value method, the mean value method, the range method and so on. The application range of each method is different. Because of the irregular settlement of the pier column, the mean value method is mainly used in this paper. At the same time, the initial value method and the absolute gray correlation degree are used to check.

\section{CALCULATION OF THE GRAY CORRELATION DEGREE BETWEEN THE CONSTRUCTION PARAMETERS AND THE DEFORMATION}

\section{Shield construction parameters.}

During the shield construction, it is necessary to control dozens of parameters mainly including the propulsion speed, the soil pressure and the quantity of grouting which are obtained by the sensors arranged in the shield. The influences of the deformation produced by these parameters in different geological conditions and different engineering conditions are different, which requires us to start from the cause of the deformation of the maglev pier columns to study the relationship between the parameters of the shield construction and the deformation of the shield, and to get the sort of its sensitivity, so as to optimize and adjust the most sensitive parameters, and then control the deformation value in the allowable range.

The data from December 1 to 11, 2017 were calculated every two days. The value of 14 main construction parameters and time dimensions are shown in Table 1.

Table 1. Construction Parameters / Comparison Sequence and Time Dimension Values

\begin{tabular}{|l|c|c|c|c|c|c|}
\hline $\begin{array}{l}\text { Construc- Date } \\
\text { tion Parameters }\end{array}$ & $\mathbf{1 2 . 0 1}$ & $\mathbf{1 2 . 0 3}$ & $\mathbf{1 2 . 0 5}$ & $\mathbf{1 2 . 0 7}$ & $\mathbf{1 2 . 0 9}$ & $\mathbf{1 2 . 1 1}$ \\
\hline $\begin{array}{l}\text { Soil pressure in the soil } \\
\text { warehouse (right) X1 } \\
(\mathrm{KPa})\end{array}$ & 231.375 & 225.546 & 208.848 & 206.689 & 212.531 & 213.264 \\
\hline $\begin{array}{l}\text { Soil pressure in the soil } \\
\text { warehouse (left) X2 } \\
(\mathrm{KPa})\end{array}$ & 243.958 & 239.286 & 232.469 & 218.796 & 230.747 & 23.820 \\
\hline $\begin{array}{l}\text { Soil pressure in the soil } \\
\text { warehouse (down) X3 } \\
\text { (KPa) }\end{array}$ & 283.583 & 283.950 & 280.082 & 267.157 & 277.054 & 281.381 \\
\hline Total thrust X4 (KN) & 13407.41 & 13530.76 & 12909.65 & 12533.29 & 12993.91 & 13446.64 \\
\hline $\begin{array}{l}\text { 'A' flow rate } \\
\text { accumulated value } \\
\text { X5 (L) }\end{array}$ & 1449.61 & 1468.13 & 1437.65 & 1369.96 & 1343.21 & 1443.27 \\
\hline
\end{tabular}




\begin{tabular}{|c|c|c|c|c|c|c|}
\hline $\begin{array}{ll}\text { Construc- } \\
\text { tion Parameters }\end{array}$ & 12.01 & 12.03 & 12.05 & 12.07 & 12.09 & 12.11 \\
\hline $\begin{array}{l}\text { Jack average speed X6 } \\
(\mathrm{mm} / \mathrm{min})\end{array}$ & 10.4292 & 10.2941 & 10.4856 & 9.9900 & 10.2614 & 10.7950 \\
\hline $\begin{array}{l}\text { Grouting accumulated } \\
(\mathrm{A}) \mathrm{X} 7\left(\mathrm{~m}^{3}\right)\end{array}$ & 1,56477 & 1.55962 & 1.50714 & 1.38591 & 1.55736 & 1.54042 \\
\hline $\begin{array}{l}\text { Cutter torque X8 } \\
(\mathrm{KN}-\mathrm{m})\end{array}$ & 1161.90 & 1099.34 & 1038.19 & 1065.33 & 1084.29 & 1004.74 \\
\hline Push pressure X9 $(\mathrm{KPa})$ & 14041.7 & 13637.0 & 13356.4 & 13157.5 & 14046.5 & 13951.0 \\
\hline $\begin{array}{l}\text { Up Push pressure } \mathrm{X} 10 \\
(\mathrm{KPa})\end{array}$ & 11977.9 & 12931.5 & 9197.9 & 10318.1 & 12301,7 & 10546.0 \\
\hline $\begin{array}{l}\text { Right Push pressure } \\
\text { X11 (KPa) }\end{array}$ & 9705.0 & 8624.8 & 8012.4 & 6243.5 & 6789.6 & 8489.1 \\
\hline $\begin{array}{l}\text { Left Push pressure X12 } \\
(\mathrm{KPa})\end{array}$ & 8648.8 & 12556.7 & 11455.1 & 9577.6 & 9885.1 & 9469.0 \\
\hline $\begin{array}{l}\text { Down Push pressure } \\
\mathrm{X} 13(\mathrm{KPa})\end{array}$ & 12853.3 & 8807.1 & 11200.4 & 12064.5 & 11170.1 & 12923.4 \\
\hline $\begin{array}{l}\text { Spiral pressureX14 } \\
(\mathrm{KPa})\end{array}$ & 5239.2 & 4951.3 & 4905.8 & 4914.7 & 4944.4 & 4805.0 \\
\hline
\end{tabular}

\section{Maglev structure facility deformation values}

For the same time period, the deformation values of the maglev facilities and the surface points are shown in Table 2.

Table 2. Pier Columns and Surface Points / Reference Sequences and Time Dimension Values

\begin{tabular}{|l|c|c|c|c|c|c|}
\hline $\begin{array}{r}\text { Total } \\
\text { settlement } \\
(\mathbf{m m})\end{array}$ & $\mathbf{1 2 . 0 1}$ & $\mathbf{1 2 . 0 3}$ & $\mathbf{1 2 . 0 5}$ & $\mathbf{1 2 . 0 7}$ & $\mathbf{1 2 . 0 9}$ & $\mathbf{1 2 . 1 1}$ \\
\begin{tabular}{|l|c|c|c|c|c|}
\hline Monitoring \\
points
\end{tabular} & & & & & & \\
\hline P0182A & 1.32 & 1.12 & 1.15 & 1.16 & 1.59 & 1.36 \\
\hline P0182B & 1.66 & 1.32 & 1.53 & 1.48 & 1.78 & 1.63 \\
\hline P0183A & 0.93 & 0.84 & 0.96 & 0.89 & 0.96 & 1.06 \\
\hline P0183B & 0.98 & 0.87 & 1.11 & 0.92 & 0.87 & 1.11 \\
\hline P0184A & 1.06 & 1.03 & 1.27 & 1.00 & 1.16 & 1.49 \\
\hline P0184B & 1.27 & 1.13 & 1.23 & 0.93 & 1.14 & 1.37 \\
\hline X01 & -1.22 & -1.31 & -0.73 & -1.36 & -1.20 & \\
\hline X03 & 2.37 & 1.87 & 0.91 & -0.81 & -3.52 & \\
\hline DB08 & 0.53 & 0.12 & -0.49 & -1.92 & -4.84 & \\
\hline
\end{tabular}




\section{Gray correlation degree calculation between construction parameters and deformation values}

According to Deng's gray correlation degree calculation method, the correlation degrees were calculated based on the values listed in Table 1 and Table 2. Gray correlation degree matrix (part) is shown in Table 3 ( $\rho$ is 0.485 ).

Table 3.Gray Correlation Degree Between Construction Parameters and Deformation Values

\begin{tabular}{|c|c|c|c|c|c|c|c|c|c|c|c|c|c|c|}
\hline $\begin{array}{l}\text { Correlation } \\
\text { Degree } \\
\text { ring } \\
\text { points }\end{array}$ & r1 & r 2 & r3 & r4 & r5 & r6 & r7 & r8 & r9 & r10 & r11 & r12 & r13 & r14 \\
\hline P0182A & 0.67 & 0.71 & 0.70 & 0.71 & 0.69 & 0.71 & 0.75 & 0.64 & 0.73 & 0.68 & 0.59 & 0.53 & 0.63 & 0.66 \\
\hline P0182B & 0.77 & 0.79 & 0.76 & 0.79 & 0.74 & 0.77 & 0.77 & 0.73 & 0.80 & 0.71 & 0.61 & 0.57 & 0.72 & 0.76 \\
\hline P0183A & 0.72 & 0.77 & 0.80 & 0.78 & 0.77 & 0.83 & 0.78 & 0.70 & 0.80 & 0.60 & 0.59 & 0.61 & 0.72 & 0.73 \\
\hline P0183B & 0.64 & 0.68 & 0.69 & 0.69 & 0.71 & 0.73 & 0.66 & 0.59 & 0.68 & 0.54 & 0.58 & 0.64 & 0.65 & 0.63 \\
\hline P0184A & 0.60 & 0.64 & 0.65 & 0.63 & 0.61 & 0.66 & 0.63 & 0.58 & 0.61 & 0.50 & 0.53 & 0.63 & 0.59 & 0.61 \\
\hline P0184B & 0.66 & 0.67 & 0.65 & 0.64 & 0.66 & 0.68 & 0.64 & 0.64 & 0.63 & 0.52 & 0.64 & 0.53 & 0.66 & 0.67 \\
\hline
\end{tabular}

\section{SENSITIVITY ANALYSIS AND COMPREHENSIVE EVALUATION}

The correlation degree matrix of the 9 reference sequences (pier column and surface deformation value) and 14 comparison sequences (shield construction parameters) is synthetically analyzed, and the conclusions are drawn as follows:

1. Comprehensive analyze the gray correlation degree matrix between the settlement value of P0182-P0184 A, B rail pier, cable ditch points, surface points and the above construction parameters, it's order is summarized as follows:

For the pier column: ranked in the top 6 parameters are $r_{6}>r_{9}>r_{2}>r_{3}>r_{4}>r_{7}$, and ranked in the last 4 are $r_{8}>r_{11}>r_{12}>r_{10}$.

For the surface points: ranked in the top 6 parameters are $r_{13}>r_{10}>r_{8}>r_{14}>r_{9}>r_{6}$, and ranked in the last 4 are $r_{5}>r_{7}>r_{12}>r_{11}$.

2. The order of above gray correlation degree shows that the sensitivity of the construction parameters for the piers and the ground points is different. For example, the most sensitive parameters for the piers are jack average speed and propulsion pressure, while the most sensitive parameters for the surface points are propulsion pressure (up) and propulsion pressure (down). Therefore, the settlement deformation can be effectively controlled by controlling the high-impact construction parameters.

3. When calculating the gray correlation degree of the strong cable trenches monitoring points, the order of the sensitivity of the construction parameters is 


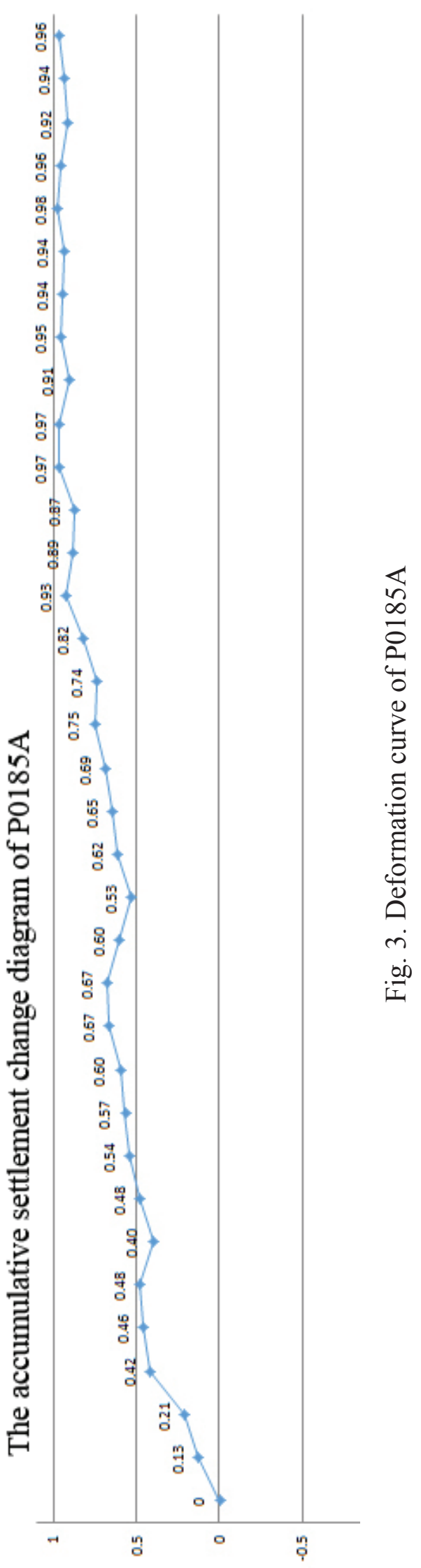


consistent with that of the piers, which may be because the strong cable trenches are located on the maglev load bearing platform, leading to their structural stability the same as that of the piers.

4. Owning to the fact that the deformation of the piers may be floating up, for the data which has both positive data and negative data, it's necessary to pretreat the data to be consistent so that the results will be closer to the actual calculation.

5. The relationship between the above construction parameters and the monitoring data is not universally applicable and only applies to the foundation of the above project. In general, for new projects, it is capable to select the appropriate test sections for simulation calculations to obtain optimal construction parameters and methods.

6. According to the above correlation degree sequencing results, the construction parameters optimization and the sensitivity control are carried out. Meanwhile, combined with the measured results of deformation monitoring, the multi means parallel monitoring data are analyzed synthetically and the data are checked, and the construction parameters are adjusted reasonably to make the pier column deformation in the controllable permissible range, having ensured the safe operation of the maglev. Among them, the deformation curve of P0185A is shown in Fig. 3. The adjustment and optimization of construction parameters can control the deformation of pier columns in the allowable range according to the order of correlation.

\section{CONCLUSIONS}

Through the calculation and analysis of the correlation degree between the pier column and the ground point settlement value of the construction parameters of the 13 shield of Shanghai subway, the most sensitive shield construction parameters are adjusted according to the degree of correlation degree, and the deformation of the shield construction to the magnetic floating structure is effectively controlled, ensuring the safe operation of the Shanghai Maglev Line. Practice has proved that, it is applicable to use Deng 's correlation degree calculation method to calculating the correlation degree of the construction parameters used in the shield-throughmaglev engineering, which is a great reference for future similar projects.

\section{ACKNOWLEDGEMENTS}

This work is supported by the National Key Technology R\&D Program of the 13th Five-year Plan, Research on Key Technologies of Medium Speed Maglev Transportation System (2016YFB1200601). 


\section{References}

1. Deng JL. Gray System Theory Tutorial. Huazhong University of Science and Technology Press. China. 1989.

2. Wu XM. Maglev Train. Shanghai Science and Technology Press. China.

3. Administrative Measures for Maglev Safety Protection Zone of Shanghai Maglev Transportation Development. Shanghai Maglev Inc. China. 2009.

4. Wang GQ, Hu ST, Ye F, Zeng GF, LV Q. Comprehensive Technical Monitoring for Maglev Structure during the Metro Shield Tunnel Undercrossing the Shanghai Maglev Protected Area. Proceedings of $18^{\text {th }}$ COTA International Conference of Transportation Professionals. China. Beijing; 2018.

5. Wang GQ, Bi S, Zeng GF, Ye F. Analysis of the influence of external construction on maglev protection area. Proceedings of the $23^{\text {th }}$ International Maglev Conference. Germany. Berlin. 2016;2:67-73.

6. Yu XD, Sun QL. Application of grey system theory in construction control of continuous girder bridge. East China Highway. 2008(5):22-23.

Information about the authors:

Wang Guo-Qiang, Doctor, Associate Researcher;

ORCID: 0000-0001-8880-6110;

E-mail:.wgq_135246@163.com

Hu Song-Tao, Bachelor;

ORCID: 0000-0003-2057-1022;

E-mail: husongtao95@126.com

Zeng Guo-Feng, Doctor, Associate Researcher;

ORCID: 0000-0001-6818-9178;

E-mail: zengguofeng@tongji.edu.cn

Ye Feng, Doctor, Associate Researcher;

ORCID: 0000-0001-8278-2170;

E-mail: yefeng@tongji.edu.cn

\section{Xu Wen-Li;}

ORCID: 0000-0001-9017-2436;

E-mail: xumenli002@163.com

\section{To cite this article:}

Wang GQ, Hu ST, Zeng GF, et al. Gray Relational Analysis Between the Maglev-Structural Deformation and Construction Parameters of the Shield Tunnel Crossing the Shanghai Maglev Protected Area. Transportation Systems and Technology. 2018;4(4):146-156. doi: 10.17816/ transsyst201844146-156. 